\title{
Seroprevalence of porcine proliferative enteropathy among wild boars in the Republic of Korea
}

Jung-Yong Yeh

\begin{abstract}
Background: The importance of the wild boar as a reservoir of Lawsonia intracellularis was assessed by investigating the seroprevalence of this pathogen among wild boars in the Republic of Korea. The extent of exposure to L. intracellularis among wild boars (Sus scrofa coreanus) was monitored by a country-wide serological survey using an immunoperoxidase monolayer assay.

Results: In this study, antibodies to L. intracellularis were observed in 165 of 716 clinically healthy wild boars tested. The overall apparent prevalence calculated directly from the sample and the true prevalence calculated based on the accuracy of the test method were $23.0 \%$ (95\% confidence interval: $20.0-26.3 \%$ ) and $25.6 \%$ (95\% confidence interval: $23.9-27.2 \%)$, respectively. Serologically positive animals were found in all the tested provinces.

Conclusions: Our results confirm that L. intracellularis is present in the wild boar population worldwide, even in Far East Asia. Despite the high seroprevalence shown in wild boars, further studies are warranted to evaluate their potential as a reservoir species because seroprevalence does not prove ongoing infection nor shedding of the bacteria in amounts sufficient to infect other animals. It should also be determined whether the wild boar, like the domestic pig, is a natural host of $L$. intracellularis.
\end{abstract}

Keywords: Lawsonia intracellularis, Serology, Wild boar

\section{Background}

Lawsonia intracellularis causes porcine proliferative enteropathy (PPE) in domestic pigs (Sus scrofa domestica), and today, PPE is present in all swine-producing areas worldwide [1]. PPE has been described as a disease most that is common among grower and finisher pigs [2]. Although pig-to-pig transmission is considered to be the primary route of infection [3], little is known about the mechanisms of transmission of $L$. intracellularis and the epidemiology of PPE, especially in wildlife. Although a few studies on L. intracellularis infection in wild boars have been conducted in European countries [4-6], similar studies from Asia are lacking. Tomanova et al. reported that L. intracellularis was present in wild boars in the Czech Republic, using PCR analysis of intestinal tissues and/or serological examination in 2002 and 2006 [4,5], whereas

Correspondence: yehjy@incheon.ac.kr

Division of Life Sciences, Incheon National University, 406-772, Academy-ro 119, Yeonsu-gu, Incheon, Republic of Korea
Jacobson et al. found no evidence of fecal shedding in the Swedish wild boar population [6]. While our manuscript was in preparation, the prevalence of antibodies to $L$. intracellularis in farmed European wild boars was also reported [7]. The aim of the present study was to assess the importance of the wild boar (Sus scrofa coreanus) population as a potential reservoir for L. intracellularis in the Republic of Korea (ROK). A nationwide prevalence survey was carried out to determine the $L$. intracellularis seroprevalence and we report the serological prevalence of $L$. intracellularis infection in captive wild boars from fields and forests in the ROK.

\section{Results and discussion}

In this study, 716 serum samples collected from clinically healthy wild boars in fields and forests were examined by immunoperoxidase monolayer assay (IPMA). Antibodies to L. intracellularis were observed in 165 wild boars. The overall apparent prevalence calculated directly from the sample and the true prevalence calculated based on the 
accuracy of the test method were $23.0 \%$ (95\% confidence interval (CI): $20.0-26.3 \%$ ) and $25.6 \%$ (95\% CI: $23.9-27.2 \%$ ), respectively. Table 1 presents the prevalence of antibodies to L. intracellularis in the wild boar population from 8 provinces in the ROK. Serologically positive animals were found in all the tested provinces. Gyeonggi province, which produces more domestic pigs than any other province in the ROK [8], and Gangwon province showed high (true) prevalence, at 38.1\% (95\% CI: 34.7\%-41.5\%) and 31.2\% (95\% CI: 27.1-35.3\%), respectively.

Previous studies have shown the presence of L. intracellularis among wild boar in Europe [4,5]. The results of the current study show that $L$. intracellularis infections also occur in wild boar populations in Asia. The previously reported prevalence of $L$. intracellularis determined by PCR analysis of intestinal tissues and/or serological examination of wild boars were as follows: $59.2 \%$ (95\% CI: 54$65 \%$ ) in farmed European wild boars [7], 20.6\% in wild boars in Germany [14], and $9.1 \%$ in wild boars in the Czech Republic [5]. The seroprevalence of this study in the wild boar population in the ROK was lower than that (56.4\%) in the domestic pig population in ROK [15].

In previous reports, Tomanova et al. assumed that wild boars are infected orally, although wild boars may not be exposed to L. intracellularis infections from feces to the same extent as domestic pigs kept under intensive farming conditions $[4,5]$. Regarding the recent publication stating that rodents may be an important reservoir of $L$. intracellularis [16], L. intracellularis could be transmitted from domestic pigs to wild animals through infected rodents, and then the infection could be maintained within individual social groups of animals, e.g., within domestic pigs or within domestic pigs, through fecal contamination. However, the possibility that wild boars infected with $L$. intracellularis could be a significant transmission source of this disease to domestic pigs cannot be ruled out. In addition, the infections may persist because wild pigs infected with L. intracellularis do not get treated with antibiotics.

The author acknowledges the limitation that seroprevalence only indicates exposure to the agent and it does not indicate ongoing infection nor does it indicate shedding of the bacteria in amounts sufficient to infect other animals. Therefore, the high seroprevalence in wild boars warrants further studies to evaluate their potential as a reservoir species.

Wild boars (Sus scrofa) are distributed throughout Asia, Europe, and Northwest Africa, and at least 16 subspecies are currently recognized [17-19]. The Korean wild boar (Sus scrofa coreanus) is a common inhabitant of fields and forests on the Korean Peninsula [20]. The results of the current study confirm that L. intracellularis is present in the wild boar population worldwide, even in Far East Asia.

\section{Conclusion}

Our results confirm that $L$. intracellularis is present in the wild boar population worldwide, even in Far East Asia. Despite the high seroprevalence shown in wild boars, further studies are warranted to evaluate their potential as a reservoir species because seroprevalence does not prove ongoing infection nor shedding of the bacteria in amounts sufficient to infect other animals. It should also be determined whether the wild boar, like the domestic pig, is a natural host of L. intracellularis.

\section{Methods}

Wild boar serum samples used

Wild boar serum sample collection took place between December 2010 and April 2011 by local governments. Samples were selected from national serum specimen resources originally obtained for the purpose of footand-mouth disease surveillance as an emergency response during the $2010 / 2011$ foot-and-mouth disease

Table 1 Seroprevalence and 95\% confidence interval for Lawsonia intracellularis in wild boars in the Republic of Korea from 2010 to 2011

\begin{tabular}{|c|c|c|c|c|c|c|}
\hline Locality & $\begin{array}{l}\text { No. of } \\
\text { tested animals }\end{array}$ & $\begin{array}{l}\text { No. of } \\
\text { positive animals }\end{array}$ & $\begin{array}{l}\text { Apparent } \\
\text { prevalence (AP) }\end{array}$ & $\begin{array}{l}\text { True } \\
\text { prevalence (TP) }\end{array}$ & $\begin{array}{l}\text { Lower } 95 \% \\
\text { confidence limit of TP }\end{array}$ & $\begin{array}{l}\text { Upper } 95 \% \text { confidence } \\
\text { limit of TP }\end{array}$ \\
\hline Gangwon & 128 & 36 & 28.1 & 31.2 & 27.1 & 35.3 \\
\hline Gyeonggi ${ }^{b}$ & 210 & 72 & 34.3 & 38.1 & 34.7 & 41.5 \\
\hline Gyeongnam ${ }^{c}$ & 58 & 16 & 27.6 & 30.7 & 24.6 & 36.7 \\
\hline Gyeongbuk $^{d}$ & 102 & 12 & 11.8 & 13.1 & 9.8 & 16.4 \\
\hline Jeonnam ${ }^{e}$ & 96 & 8 & 8.3 & 9.2 & 6.3 & 12.1 \\
\hline Jeonbuk & 23 & 3 & 13.0 & 14.4 & 7.2 & 21.7 \\
\hline Chungnam $^{f}$ & 32 & 6 & 18.8 & 20.9 & 13.8 & 28.0 \\
\hline Chungbuk & 67 & 12 & 17.9 & 19.9 & 15.1 & 24.7 \\
\hline Total & 716 & 165 & 23.0 & 25.6 & 23.9 & 27.2 \\
\hline
\end{tabular}

${ }^{\mathrm{a}} \mathrm{TP}=(\mathrm{AP}+$ specificity-1)/(sensitivity + specificity-1) [9-12]. Specificity and sensitivity of the test employed in this study were according to the previous report [13]. ${ }^{b}$ Seoul Metropolis and Incheon Metropolitan City included; ${ }^{C}$ Ulsan and Busan Metropolitan Cities included; ${ }^{d}$ Daegu Metropolitan City included; ${ }^{e}$ Gwangju Metropolitan City included; 'Daejeon Metropolitan City included. 
epidemic [21,22]. Original wild serum samples were collected with the help of hunters, farm workers, or local government officers under the Korea National Animal Health Monitoring Project. Blood from the pericardium or thoracic cavity was taken immediately after killing them or if the wild boars were caught alive, the blood samples for serological analyses were taken by venipuncture from the vena cava cranialis, vena jugularis or the ear vein. Whole blood was collected in 5-ml plastic EDTA tubes, and whole blood for serum was collected in 10-ml plastic blood serum tubes. The tubes were cooled after sampling and sent to the laboratory of the Animal, Plant, and Fisheries Quarantine and Inspection Agency, Anyang, Gyeonggi-do. Blood and serum samples were stored at $70^{\circ} \mathrm{C}$ and $-20^{\circ} \mathrm{C}$, respectively, until examination. In this study, only serum samples were tested for detection of antibodies against $L$. intracellularis using IPMA. All provinces in ROK were included in this study (Table 1). Sample size calculations were performed using the following formula $[9,23,24]: n=\left[Z_{1-\mathrm{a} / 2} / d(S e+S p-1)\right]^{2} p(1-p)$, where $S e$ and $S p$ are the sensitivity and specificity of the test, respectively, and $p$ is the assumed prevalence. Although we tried to estimate the assumed prevalence from published data on L. intracellularis positivity in the wild boar population, the range of prevalence previously reported was wide, from 59.2 to $9.1 \%[5,7,14]$. Because there were no consistent data on the infection frequency when this study was being planned, the necessary sample size was based on an assumed prevalence of $p=0.50$ to maximize the sample size. A minimal sample size of 208 at the $95 \%$ confidence level was required according to the above formula.

\section{IPMA}

Blood samples were examined for the presence of antibodies against $L$. intracellularis by IPMA. Using the pathogenic isolate PHE/KK421 (Korean Collection for Type Cultures 10686BP) [25], IPMA was performed as previously described [26]. Briefly, the acetone-methanol-fixed L. intracellularis culture plate was incubated with sera diluted 1:30 in phosphate-buffered saline (PBS) for $30 \mathrm{~min}$ at $37^{\circ} \mathrm{C}$ and washed 5 times with PBS, pH 7.2. Peroxidase-labeled goat anti-porcine IgG was diluted 1:1000 (KPL, MD, USA) in 2\% bovine serum albumin and $0.08 \%$ Tween 80 in PBS and then added at a concentration of $30 \mu \mathrm{L} /$ well. The plate was incubated for $45 \mathrm{~min}$ at $37^{\circ} \mathrm{C}$. The plate was washed again, and a chromogenic (3-amino-9-ethyl-carbazole, Dako Corporation, CA, USA) solution was added to each well. The plate was then incubated at room temperature for $20 \mathrm{~min}$. The plate was washed with distilled water three times, allowed to dry, and examined using an inverted light microscope (Olympus, Tokyo, Japan). L. intracellularis-positive and L. intracellularisnegative antiserum controls and a secondary antibody control were included on each plate. Positive samples contained red-labeled bacteria, both in the cytoplasm of infected McCoy cells and in the supernatant. Negative control plates using mock-infected cells were included for each individual serum sample to avoid false-positive results.

True prevalence (TP) was estimated, as described by Marchevsky et al. [9-12], using published IPMA test sensitivity and specificity of $100 \%$ and $90 \%$, respectively [26]. The formula used to determine TP was: $\mathrm{TP}=($ apparent prevalence + specificity-1)/(sensitivity + specificity-1). Statistical analyses were performed with the NCSS 2007 Statistical Software package (NCSS Statistical System for Windows, Kaysville, UT, USA) and the program 'Survey Toolbox Version 1.04' [27].

\section{Competing interests}

The author declares that he has no competing interests.

\section{Authors' contributions}

JYY conceived of the study, designed the experiments, conducted the majority of the experiments in the laboratory including the cultivation of $L$. intracellularis and McCoy cells and IPMA, wrote the manuscript, conducted analysis of wild boar serum samples and data results, and finalized the manuscript.

\section{Acknowledgements}

This work was supported by the Animal, Plant, and Fisheries Quarantine and Inspection Agency, RO Korea (grant \#: 6235-320-210-13). The author is very grateful to the local government veterinary officers for the help in collecting samples of wild boars from all over the country.

Received: 13 December 2012 Accepted: 2 January 2014 Published: 6 January 2014

\section{References}

1. McOrist S, Gebhart CJ: Proliferative Enteropathies. In Diseases of Swine. 9th edition. Edited by Straw BE, Zimmerman JJ, D'Allaire S, Taylor DJ. USA: Blackwell Publishing; 2006:727-737.

2. NAHMS: Highlights of NAHMS Swine 2000:Part II. USA: USDA:APHIS; 2002

3. Jordan DM, Knittel JP, Schwartz KJ, Roof MB, Hoffman LJ: A Lawsonia intracellularis transmission study using a pure culture inoculated seeder-pig sentinel model. Vet Microbiol 2004, 104(1-2):83-90.

4. Tomanova K, Bartak P, Smola J: Detection of Lawsonia intracellularis in wild pigs in the Czech Republic. Vet Rec 2002, 151(25):765-767.

5. Dezorzova-Tomanova K, Smola J, Trcka I, Lamka J, Pavlik I: Detection of Lawsonia intracellularis in wild boar and fallow deer bred in one game enclosure in the Czech Republic. J Vet Med B Infect Dis Vet Public Health 2006, 53(1):42-44.

6. Jacobson M, Gerth Lofstedt M, Holmgren N, Lundeheim N, Fellstrom C: The prevalences of Brachyspira spp. and Lawsonia intracellularis in Swedish piglet producing herds and wild boar population. J Vet Med B Infect Dis Vet Public Health 2005, 52(9):386-391.

7. Halli O, Ala-Kurikka E, Nokireki T, Skrzypczak T, Raunio-Saarnisto M, Peltoniemi $\mathrm{OA}$, Heinonen M: Prevalence of and risk factors associated with viral and bacterial pathogens in farmed European wild boar. Vet $\mathrm{J} 2012$, 194(1):98-101.

8. Korea_National_Statistical_Office: Livestock statistics, September 2008. In Edited by KNS Office. Daejeon, Republic of Korea: Statistics Korea; 2008

9. Rogan WJ, Gladen B: Estimating prevalence from the results of a screening test. Am J Epidemio/ 1978, 107(1):71-76.

10. Marchevsky N: Errors in prevalence estimates in population studies: a practical method for calculating real prevalence. Zoonosis 1974, 6:98-109.

11. Hilden J: A further comment on "Estimating prevalence from the results of a screening test". Am J Epidemiol 1979, 109(6):721-723.

12. Shoukri MM, Edge VL: Statistical methods for health sciences. Boca Raton, FL: CRC Press; 1996

13. Collins A, Gonsalves J, Fell S, Barchia I: Comparison of a commercial ELISA with an indirect fluorescent antibody test to detect antibodies to 
Lawsonia intracellularis in experimentally challenged pigs. Aust Vet J 2012, 90(3):97-99.

14. Reiner $G$, Winkelmann M, Willems H: Prevalence of Lawsonia intracellularis, Brachyspira hyodysenteriae, and Brachyspira pilosicoli infection in hunted wild boars (Sus scrofa) in Germany. Eur J Wildl Res 2011, 57:443-448.

15. Lee SW, Kim TJ, Park SY, Song CS, Chang HK, Yeh JK, Park HI, Lee JB: Prevalence of porcine proliferative enteropathy and its control with tylosin in Korea. J Vet Sci 2001, 2(3):209-212.

16. Collins AM, Fell S, Pearson H, Toribio JA: Colonisation and shedding of Lawsonia intracellularis in experimentally inoculated rodents and in wild rodents on pig farms. Vet Microbiol 2011, 150:384.

17. Mason IL: Pig. In Evolution of Domesticated Animals. London: Longman; 1984:145-162.

18. Herre W, Rohrs M: Zoological considerations on the origins of farming and domestication. In Origins of Agriculture. Edited by Reed CA. The Hague: Mouton; 1977 .

19. Rothschild MF, Ruvinsky A: Systematics and evolution of the pig. In The Genetics of the Pig. Edited by Rothschild MF, Ruvinsky A. Oxfordshire: CAB International; 1998:1-16.

20. Cho IC, Han SH, Fang M, Lee SS, Ko MS, Lee H, Lim HT, Yoo CK, Lee JH, Jeon JT: The robust phylogeny of Korean wild boar (Sus scrofa coreanus) using partial D-loop sequence of mtDNA. Mol Cells 2009, 28(5):423-430.

21. ProMED-mail: Foot \& mouth disease - S Korea (09): (KB) OIE. In International Society for Infectious Diseases. Amsterdam, Netherlands: Elsevier Science BV; 2010.

22. ProMED-mail: Foot-and-mouth disease - $\mathrm{S}$. Korea (16): (North Gyeongsang) OIE. 20110504.1376. In International Society for Infectious Diseases. London and New York: Longman; 2011.

23. Rahme $E$, Joseph $L$ : Estimating the prevalence of a rare disease: adjusted maximum likelihood. The Statistician 1998, 47(1):149-158.

24. Dendukuri N, Rahme E, Belisle P, Joseph L: Bayesian sample size determination for prevalence and diagnostic test studies in the absence of a gold standard test. Biometrics 2004, 60(2):388-397.

25. Yeh JY, Kim TJ, Park SY, Song CS, Yoon YD, Kim SK, Lee JB, Choi IS: Isolation of Lawsonia intracellularis in Korea and reproduction of proliferative enteropathy in pigs and hamsters. J Vet Med Sci 2006, 68(5):499-501.

26. Guedes RM, Gebhart CJ, Deen J, Winkelman NL: Validation of an immunoperoxidase monolayer assay as a serologic test for porcine proliferative enteropathy. $J$ Vet Diagn Invest 2002, 14(6):528-530.

27. Survey Toolbox Version 1.04. http://www.ausvet.com.au/content.php? page $=$ software\#st.

doi:10.1186/1746-6148-10-5

Cite this article as: Yeh: Seroprevalence of porcine proliferative enteropathy among wild boars in the Republic of Korea. BMC Veterinary Research 2014 10:5.

\section{Submit your next manuscript to BioMed Central and take full advantage of:}

- Convenient online submission

- Thorough peer review

- No space constraints or color figure charges

- Immediate publication on acceptance

- Inclusion in PubMed, CAS, Scopus and Google Scholar

- Research which is freely available for redistribution 